\title{
Esthetic Rehabilitation of Familial Hypodontia: A Case Report
}

\author{
Dali $M,{ }^{1 *}$ Shrestha $S,{ }^{2}$ Rajbanshi $L K^{3}$
}

\section{Affiliation:}

1. Associate Professor, Department of Pedodontics \& Preventive Dentistry, B. P. Koirala Institute of Health Sciences, Dharan-18, Sunsari, Nepal.

2. Assistant Professor Department of Pedodontics, B. P. Koirala Institute of Health Sciences, Dharan-18, Sunsari, Nepal.

3. Lecturer, Department of Anesthesia an Critical Care, Birat Medical College \& Teaching Hospital, Biratnagar, Nepal.

\section{ARTICLE INFO}

\section{Article History}

Received : 14 Sept, 2016

Accepted : 29 Sept, 2016

Published : 20 Dec, 2016

(C) Authors retain copyright and grant the journal right of first publication with the work simultaneously licensed under Creative Commons Attribution License CC - BY 4.0 that allows others to share the work with an acknowledgement of the work's authorship and initial publication in this journal.

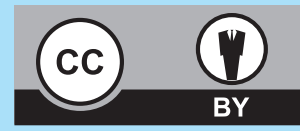

* Corresponding Author

Dr Mamta Dali

Associate Professor

Department of Pedodontics and Preventive Dentistry

B. P. Koirala Institute of Health Sciences

Dharan-18, Sunsari, Nepal

Email: mamtadali@hotmail.com

\section{Citation}

Dali M, Shrestha S, Rajbanshi LK. Esthetic Rehabilitation of Familial Hypodontia: A Case Report. BJHS 2016; 1 (1) 1: 71-74.

\section{ABSTRACT}

Dental agenesis is the most common developmental anomaly in humans and is frequently associated with several other oral abnormalities. In the literature, some terms are used to describe missing teeth like oligodontia, anodontia and hypodontia. Hypodontia is the developmental absence of one or more teeth. It can be isolated or as a part of a syndrome such as in ectodermal dysplasia. The consequences of missing teeth include abnormal occlusion or altered facial appearance which can cause psychological distress in some patients. The present case report describes case of familial hypodontia in 14 years female patient with no apparent systemic abnormalities.

\section{KEY WORDS}

Familial hypodontia, prosthetic rehabilitation, tooth agenesis 


\section{INTRODUCTION}

Hypodontia is the developmental absence of one or more teeth. ${ }^{1}$ In the permanent dentition, prevalence has been reported to range from $2.3 \%$ to $11.3 \%$ depending on the population investigated and females are affected more frequently than males by a ratio of 3:2 with no difference in the distribution of missing teeth over maxilla/mandible and left and right sides. ${ }^{2}$ Hypodontia is observed as an isolated trait (an autosomal dominant form) or as part of a syndrome such as ectodermal dysplasia and Down syndrome. ${ }^{3}$ There is still no precise description of the casual factors underlying the lack of formation of certain teeth. The most likely factors however are hereditary, environmental factors and evolution. ${ }^{4,5}$ Several mechanisms have been implicated as causes of hypodontia. Physical disruption of the dental lamina may result in obliteration of tooth buds and agenesis of teeth. There may be a metabolic imbalance of such nature that a crucial metabolite for odontogenesis is absent and agenesis results. ${ }^{6}$ The absence of teeth in young patients can cause aesthetic, functional, and psychological problems particularly if the teeth of the anterior region are involved. ${ }^{7}$ This study reports a case of 14 years female patient presented with familial hypodontia where esthetic and functional rehabilitation was established through prosthetic rehabilitation.

\section{CASE REPORT}

A 14 years old female patient with an interesting presentation of multiple congenitally missing permanent teeth in maxilla and mandible was referred to Department of pedodontics and preventive dentistry for esthetic rehabilitation (Figure 1a,1b,1c).
Medical history revealed absence of any systemic diseases or syndrome. However when questioned about similar presentation in the family, it was found that her mother and brother also had congenital missing teeth. The patient had normal facial appearance without any physical or skeletal abnormality. Patient was born to non-consanguineous parents. There was no history of any infection or trauma to the anterior region. The patient's dental condition was evaluated on the basis of shape, size, number of teeth, state of changes of dental hard tissues and occlusal anomalies. Suspecting the congenital absence of permanent teeth panoramic radiograph was taken which showed congenita absence of permanent maxillary and mandibular incisors and permanent tooth buds of all third molars $(12,18$, $21,22,28,31,32,38,41,42,48)$ and retained deciduous teeth $52,53,63,73,83$ (Figure 2). As the retained deciduous teeth were still firm without evidence of root resorption, no extraction was done.

Based on clinical and radiological examinations, diagnosis of nonsyndromic familial hypodontia was made. The condition was explained to the patient and treatment plan was discussed. A removable partial denture was fabricated for the maxillary and mandibular arch as an intermediate procedure to restore esthetics and the masticatory function (Figure 3a, 3b).

The patient is to be monitored every six months to determine the need to refit or remake of removable partial prosthetic appliance. Implants and fixed prosthesis are recommended later in life after the completion of jaw growth (Figure 4a, 4b).

Figure 1: Clinical photograph of maxillary and mandibular arch showing multiple missing teeth
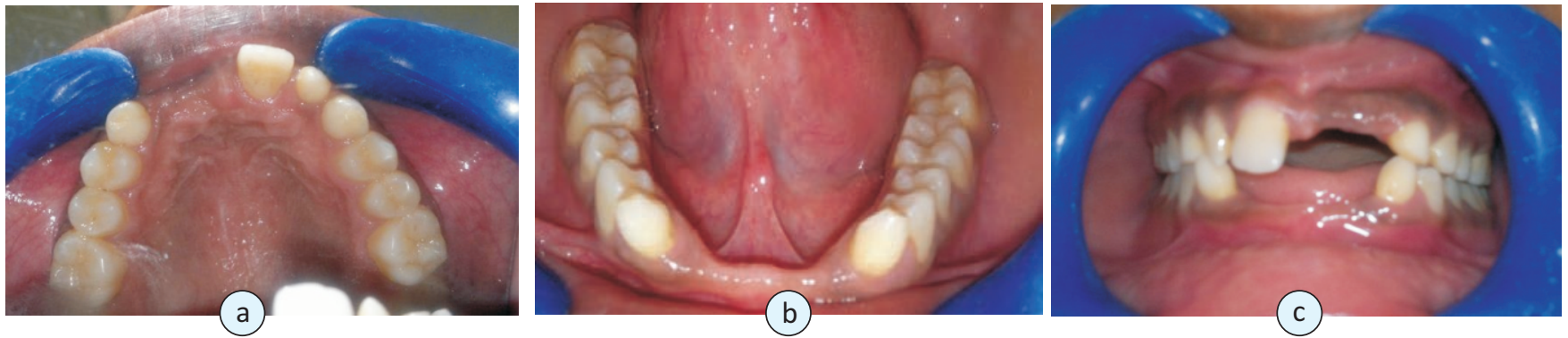
Figure 2: OPG revealing hypodontia of $12,18,21,22,28,31,32,38,41,42,48$ and retained deciduous teeth $52,53,63,73,83$

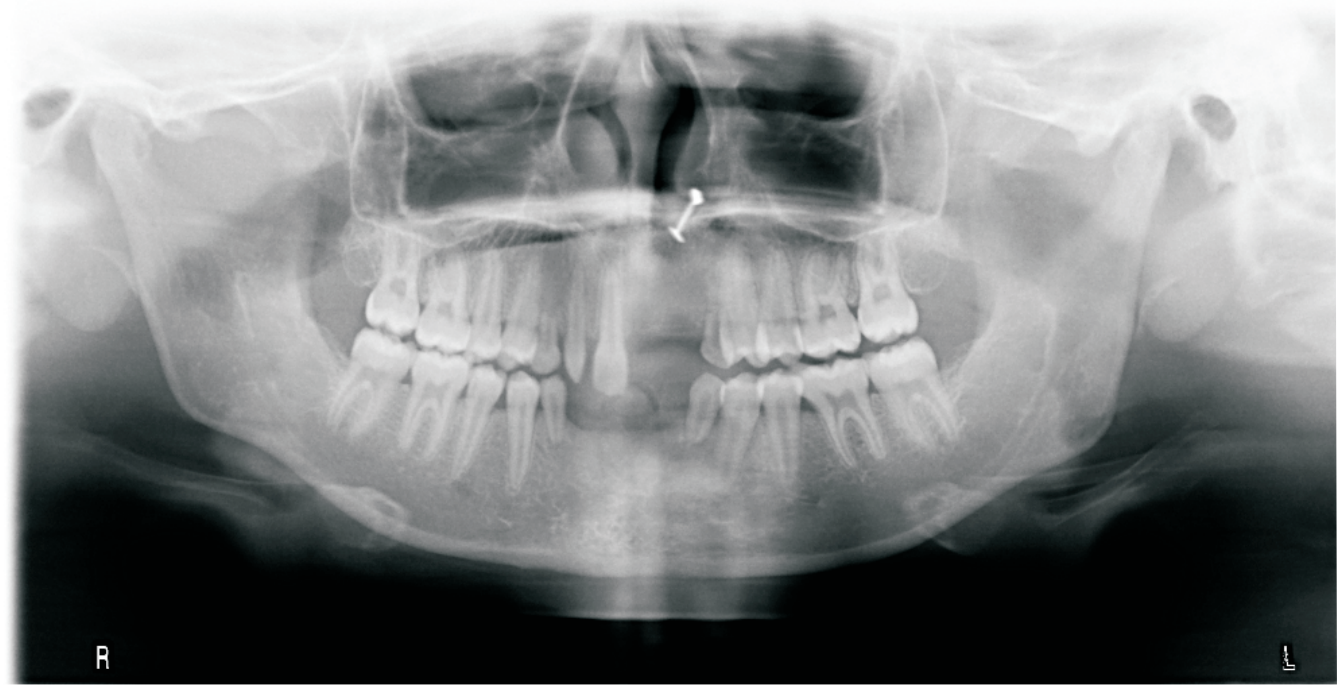

Figure 3 : Postoperative view after prosthesis placement in maxillary and mandibular arches

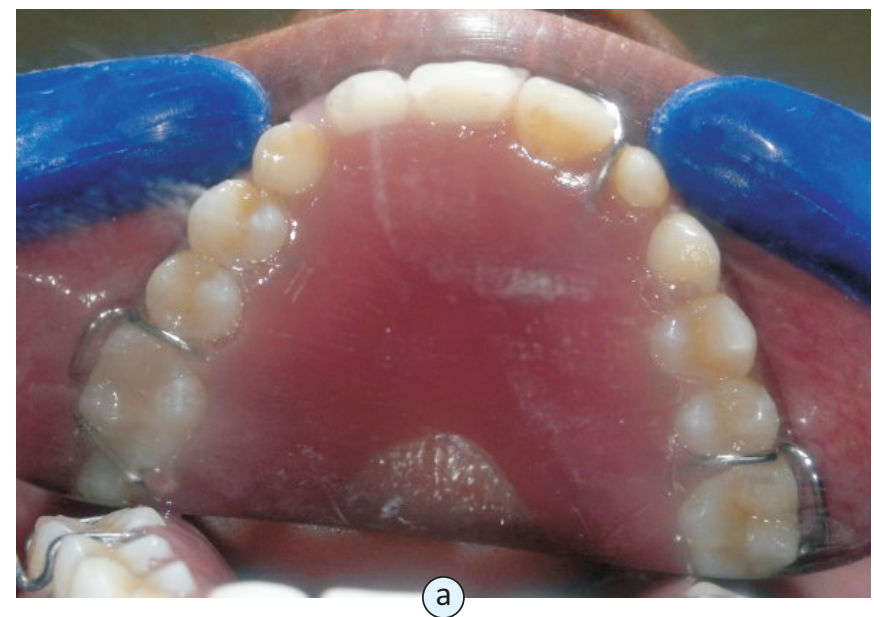

(a)

Figure 4 : Preoperative and Postoperative facial view

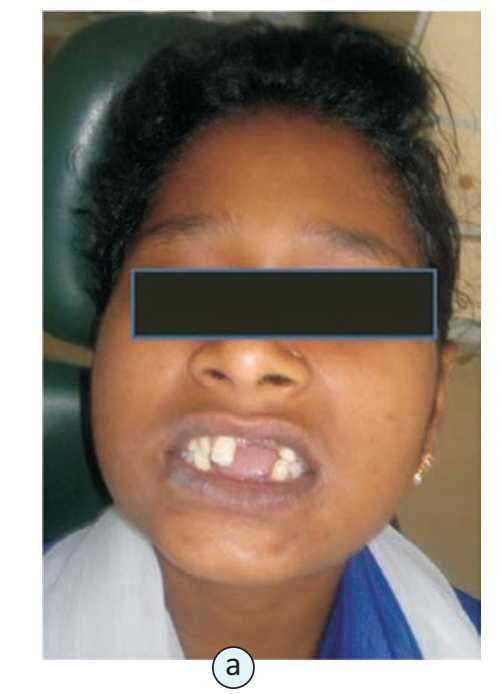

(a)

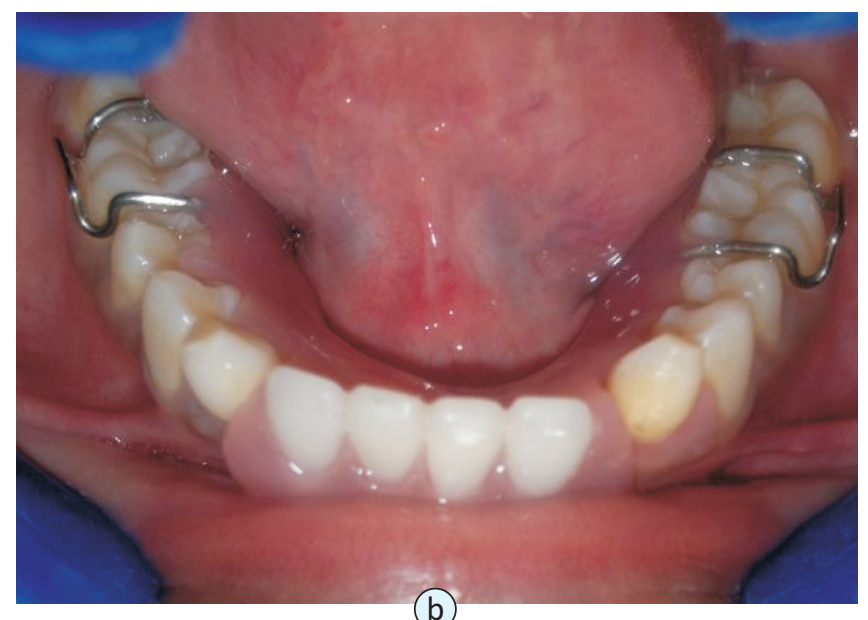

(b)

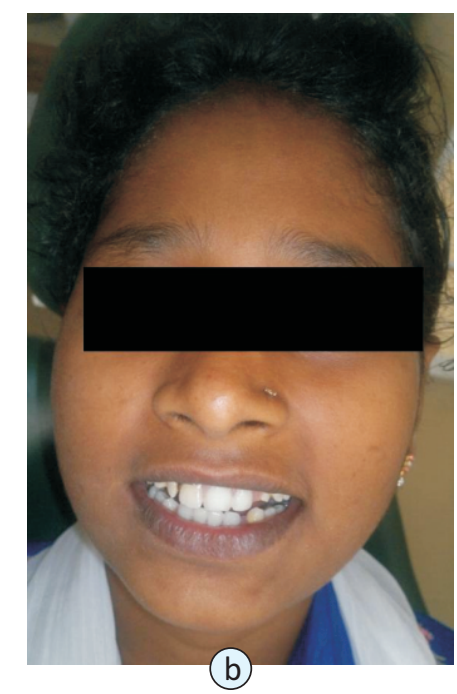




\section{DISCUSSION}

A tooth is defined to be congenitally missing if it has not erupted in the oral cavity and is not visible in a radiograph. ${ }^{8}$ In general hypodontia is the term most frequently used when describing the phenomenon of congenitally missing teeth. Hypodontia is an anomaly that may result in dental malpositioning, periodontal damage, lack of development of maxillary and mandibular bone height and has significant psychological, aesthetic and functional consequences. ${ }^{9}$ According to a 1996 consensus conference on oral implants in young patients, the following definitions are used; Hypodontia is defined as the absence of one to five permanent teeth, while the term oligodontia refers to the absence of six or more permanent teeth and 'anodontia' to the absence of all permanent teeth. ${ }^{10}$ Oligodontia as well as hypodontia (lack of one or more permanent teeth) are highly heritable conditions associated with mutations in the AXIN2, MSX1, PAX9, EDA and EDAR genes. ${ }^{11}$ Some dental anomalies have been reported together with congenitally missing teeth, however in our case, no anomalies were found. This case report illustrates the need for a multidisciplinary team approach to care, not only at the treatment planning stage, but also throughout the entire course of treatment. The main objectives in the management of any hypodontia case are to improve esthetics and restore masticatory function, both were achieved in this case. Given that the patient presented in early adolescence, the timing of treatment and the coordination of care were additional critical components. Treating such patient requires a thorough knowledge of growth and development and long term follow up is necessary for the modification and/or replacement of the prosthesis. Adjustments related to fit of prosthesis and occlusion must be monitored periodically at regular intervals due to jaw growth. When growth is stabilized, osseointegrated implants may be an alternative aid to support, stabilize, and retain the prosthesis. ${ }^{12}$ There are also reports on teeth autotransplantation. It applies to patients with hypodontia in one arch and crowded teeth in the other. $^{13}$

\section{CONCLUSION}

Early diagnosis of abnormalities in the number of teeth is very important, not only from the aspect of aesthetics, but above all from the aspect of health. The co-operation within an interdisciplinary team (pedodontist and prosthodontist) is necessary and very important in early treatment planning. Additionally excellent communication with patients and parents is necessary, as the treatment duration for patients with hypodontia may extend over many years.

\section{REFERENCES}

1. Whittington BR, Durward CS. Survey of anomalies in primary teeth and their correlation with the permanent dentition. N Z Dent J $1996 ; 92(407): 4-8.2$

2. Larmour CJ, Mossey PA, Thind BS, Forgie AH, Stirrups DR. Hypodontia - a retrospective review of prevalence and etiology. Part 1. Quintessence Int 2005; 36(4):263-70.6

3. Das $P$, Stocton D W, Baer C, Shaffer L G, D'Souza R N, Wright J T: Haploinsufficiencyof PAX9 is associated with autosomal dominant hypodontia. Human Genet 2002, 110: 371-376.

4. Gravely J.F and Johnson D.B : Variation in the expression of hypodontia in monozygotic twins. Dent Pract 1971;21:212

5. Brook AA. : A Unifying aetiological explanation for anomalies of human tooth number and size Arch Oral boil 1984:29;373-8.

6. Dixon G.H, Stewart R.E. Genetic aspects of anomalous tooth developments. OralFacial Genetics, St. Louis: Mosby Co.,1976.

7. Stewart RE, Witkop Jr CJ, Bixler D. The dentition and anomalies of tooth size, form, structure, and eruption. In: Stewart RE, Barber TK, Troutman KC, Wei SHY, eds. Pediatric Dentistry: Scientific Foundations of Clinical Procedures. 1st ed. St Louis: CV Mosby Co; 1982:87-109.

8. White SC, Pharoah MJ. Oral radiology principles and interpretation. In: WhiteSC(Ed). Dental anomalies. St.Louis, PA: Mosby; 2000:305-306.

9. Cakur B, Dagistan S, Milgolu and Bilge M. Nonsyndromic Oligodontia in Permanent Dentition: Three Siblings. The Internet Journal of Dental Science 2006;3.

10. Durstberger G, Celar A, Watzek G. Implant-surgical and prosthetic rehabilitation of patients with multiple dental aplasia: a clinical report. Int J Oral Maxillofac Implants 1999;14:417-23.

11. Bergendal B, Klar J, Stecksén-Blicks C, Norderyd J, Dahl N. Isolated oligodontia associated with mutations in EDARADD, AXIN2, MSX1 and PAX9 genes. Am J Med Genet A 2011;155A :1616-22.

12. Piegno MA, Blackman RB, Cronin RJ, Cavazos E. Prosthodontic management of Ectodermal Dysplasia: A review of its literature. J Prosthet Dent 1996;76:541-5.

13. Kaczmarek U.: Auto-transplantation of teeth. Dent. Med. Probl. 2006,43, 277-281. 